Supplement of Ocean Sci., 15, 83-96, 2019 https://doi.org/10.5194/os-15-83-2019-supplement C Author(s) 2019. This work is distributed under the Creative Commons Attribution 4.0 License.

(c) (1)

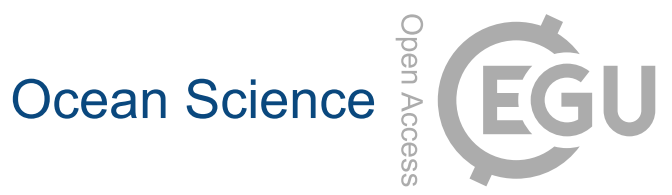

Supplement of

\title{
Frontogenesis of the Angola-Benguela Frontal Zone
}

Shunya Koseki et al.

Correspondence to: Shunya Koseki (shunya.koseki@gfi.uib.no)

The copyright of individual parts of the supplement might differ from the CC BY 4.0 License. 


\section{Supplemental Information for Koseki, Giordani and Goubanova}

\section{Procedure to estimate climatology of OFGF}

In this study, we used CFSR 6-hourly data. For calculation of the OFGF climatology, in the first place, we estimated daily-mean quantities of velocity and temperature for each year from 1979 to 2010 . For each year, using these daily-mean data, all terms of the OFGF were calculated. Then, the daily-climatology of the OFGF was calculated.

\section{Supplemental figures}

(a) Meridional gradient of

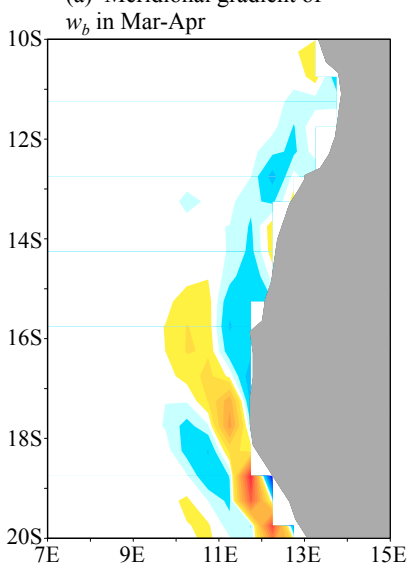

(c) OML depth difference between

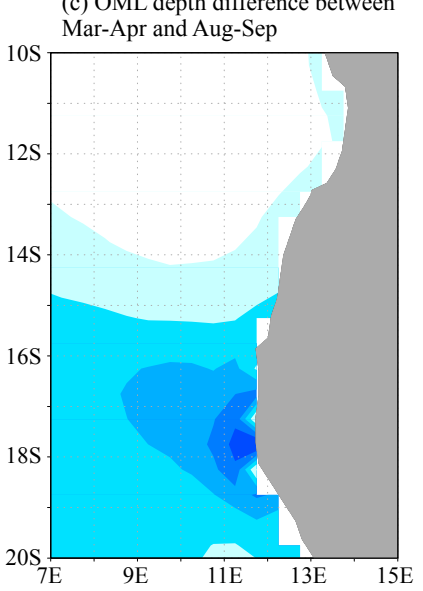

(b) Meridional gradient of

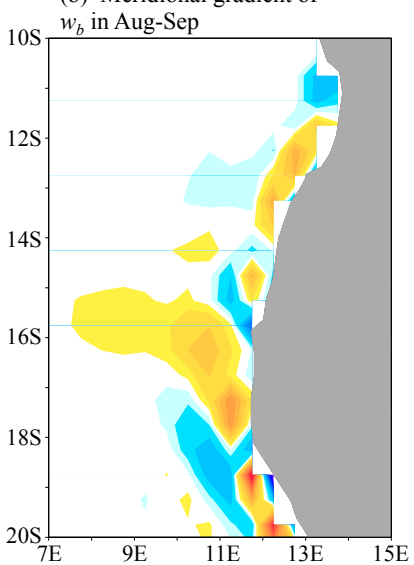

(d) Stratification difference

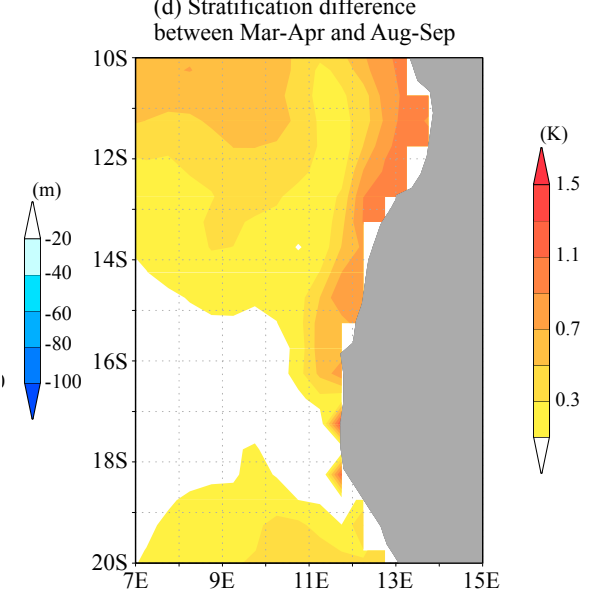

Figure S1. Meridional gradient of the vertical motion at the bottom of OML for (a) March-April mean and (b) August-September means. (c) Difference in OML depth ( $D$ in Eq. 3.5)between March-April and August-September mean. (d) Difference in upper ocean stratification ( $\Delta \theta$ in Eq 3.5) between MarchApril and August-September mean. 
(a)

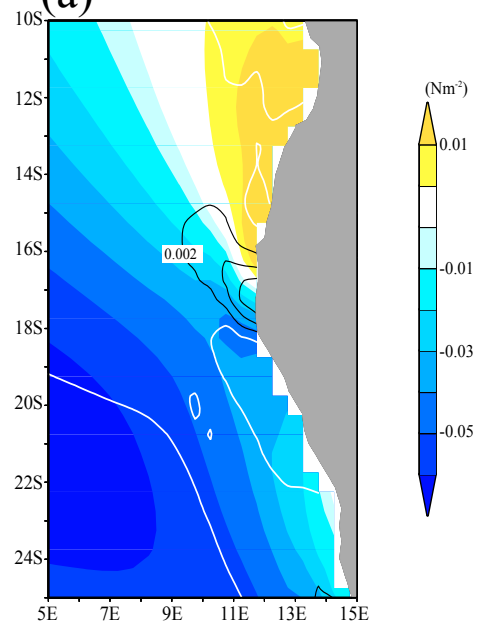

(c)

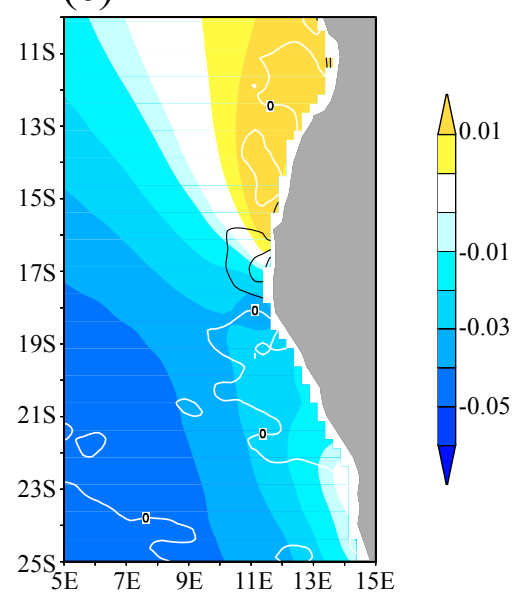

(b)

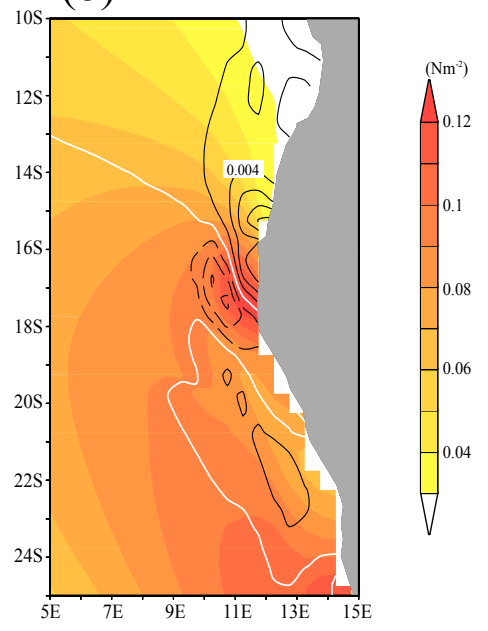

(d)

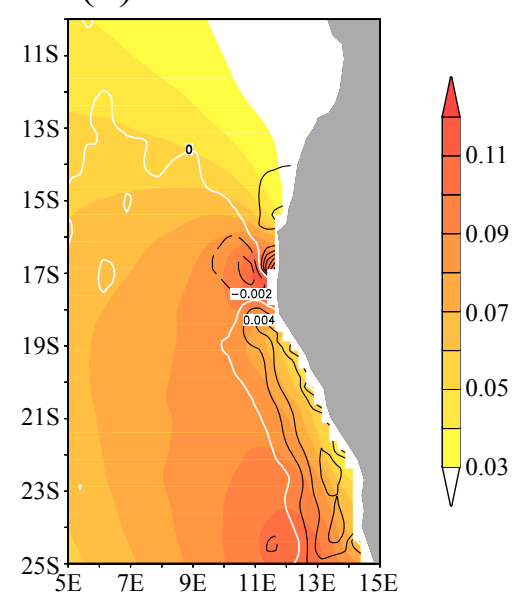

Figure S2.

Annual-mean climatology of zonal and meridional wind stress for CFSR ((a) and (b)) and SCOW ((c) and (d)). The contours denote the Ekman divergence associated with wind stress. The solid (dashed) lines are positive (negative). 